\title{
Spray Structure of an Elliptical Effervescent Atomizer
}

\author{
Sana Shaghaghian ${ }^{1}$, Mehdi Jadidi ${ }^{1}$, Ali Dolatabadi ${ }^{1}$ \\ ${ }^{1}$ Department of Mechanical and Industrial Engineering, Concordia University \\ Montreal, QC, Canada, H3G 2W1 \\ sana.shaghaghian@mail.concordia.ca; m_jadi@encs.concordia.ca; ali.dolatabadi@concordia.ca
}

\begin{abstract}
The spray structure of an effervescent atomizer with an elliptical orifice is studied using the high-speed shadowgraphy technique. The major to minor axis ratio of the ellipse is 3. The effect of gas to liquid ratios (GLR) in the range of $0.55-2.55 \%$ on the spray angle is analyzed. The water flow rate was constant for all the tests, while the airflow rate varied. Two imaging views of minor and major axes were captured for each test condition. This study shows that an increase in the gas flowrate results in an increase in the spray angle from both imaging views. It was shown that the spray angle from the minor view is wider than that of the major view, and the difference magnifies by increasing the GLR.
\end{abstract}

Keywords: Elliptical effervescent atomizer; Outside-in gas injection; Two-phase flow; Spray angle; Gas to liquid ratio; High-speed imaging.

\section{Introduction}

An effervescent atomizer, which can be categorized as twin-fluid atomizers, mixes two phases of gas and liquid internally. The atomizing gas is injected into the flowing liquid at a low velocity to create a mixture of bubbly two-phase flow in the mixing chamber before the nozzle exit [1]. Numerical simulation provides an understanding of the internal and external flows in this kind of nozzles [2]. Effervescent atomizers have been used in various engineering applications, such as internal combustion engines, gas turbine combustors, pharmaceutical processes, agricultural sprays, and thermal spray coatings, where pure liquid or complex fluids should be fragmented into small droplets.

Spray angle, which demonstrates the coverage region of the spray, is one of the essential characteristics of atomization influencing the performance of a nozzle. In general, the atomizer type and its dimensions, ambient air pressure, and liquid properties influence the spray angle. Chen and Lefebvre [3] investigated the effect of liquid properties and ambient pressure on the spray angle of the effervescent atomizer. They observed that for ambient pressures bellow $0.5 \mathrm{MPa}$, a continuous increase in gas to liquid mass ratio causes the spray angle to rise to a maximum value and then gradually decreases. While at high ambient air pressures, an increase in GLR causes a slight rise in the spray angle. In addition, they showed that lower viscosity and surface tension results an increase in spray angle. Other studies showed that when GLR increases, the spray angle widens because a higher amount of energy exists for aeration gas as it leaves the nozzle orifice [4], [5].

Using noncircular nozzles can be effective due to their improved atomization performance and shorter breakup length [6]. It has been recently demonstrated that the spray angle in the elliptical nozzles is larger than in the circular nozzles [7].

In the present study, the spray angle of an effervescent nozzle with an elliptical orifice is investigated at various GLRs and constant ambient air pressure. The shadowgraph images were used to measure the spray angle with an image processing technique. For each test condition, two different views of the elliptical nozzle are considered.

\section{Experimental setup}

\section{1. Atomizer geometry}

The effervescent nozzle used in this study has an outside-in gas injection configuration, which provides a large liquid flow area to prevent clogging when the nozzle is used for complex fluids such as suspensions [8]. This configuration has been frequently used in previous studies [9] [10] [11]. In this design, the liquid flows through an internal tube, and the aeration gas, which flows around the central tube, is injected into the liquid by some small holes on the inner tube. Fig. 1 shows the schematic of this nozzle. 24 aeration holes with a $1 \mathrm{~mm}$ diameter are used to inject gas into the mixing chamber. 
The exit orifice has an elliptical shape with the major, minor, and equivalent diameter of $2.03 \mathrm{~mm}, 0.67 \mathrm{~mm}$, and 1.17 $\mathrm{mm}$, respectively.

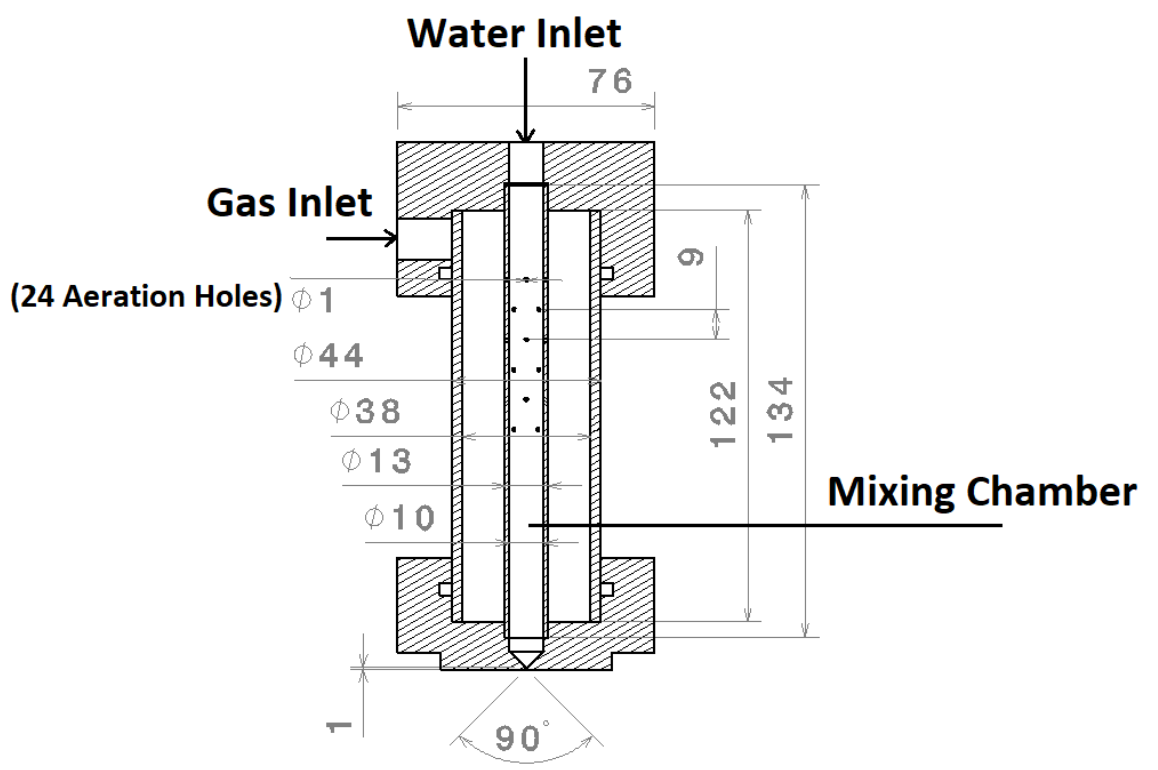

Fig. 1: Schematic of the effervescent atomizer (units are in $\mathrm{mm}$ ).

\section{2. Test conditions}

Fig. 2 shows the schematic of the experimental setup, which consists of a liquid pressure vessel, water flowmeter, gas flowmeter, air supply system, effervescent atomizer, high-speed camera, and light source. Distilled water is used as the test liquid. A high-speed camera (Photron S A1.1) with $3 \mu \mathrm{sec}$ shutter speed and 5000 frames per second with a resolution of $1024 \times 1024$ pixels and a lens (AF Micro-Nikkor $105 \mathrm{~mm} \mathrm{f/2.8)}$ are used to record the images from two sides of the spray, major and minor axis views. For the backlight, an LED light (120 W, Schott, California USA) is utilized. The water flowrate is kept constant at $397 \mathrm{~mL} / \mathrm{min}$, and the gas flow rate varies from approximately 2000 to $8500 \mathrm{~mL} / \mathrm{min}$. Table 1 demonstrates the 8 test conditions. The distance between the spray and the camera lens was kept at $15 \mathrm{~cm}$.

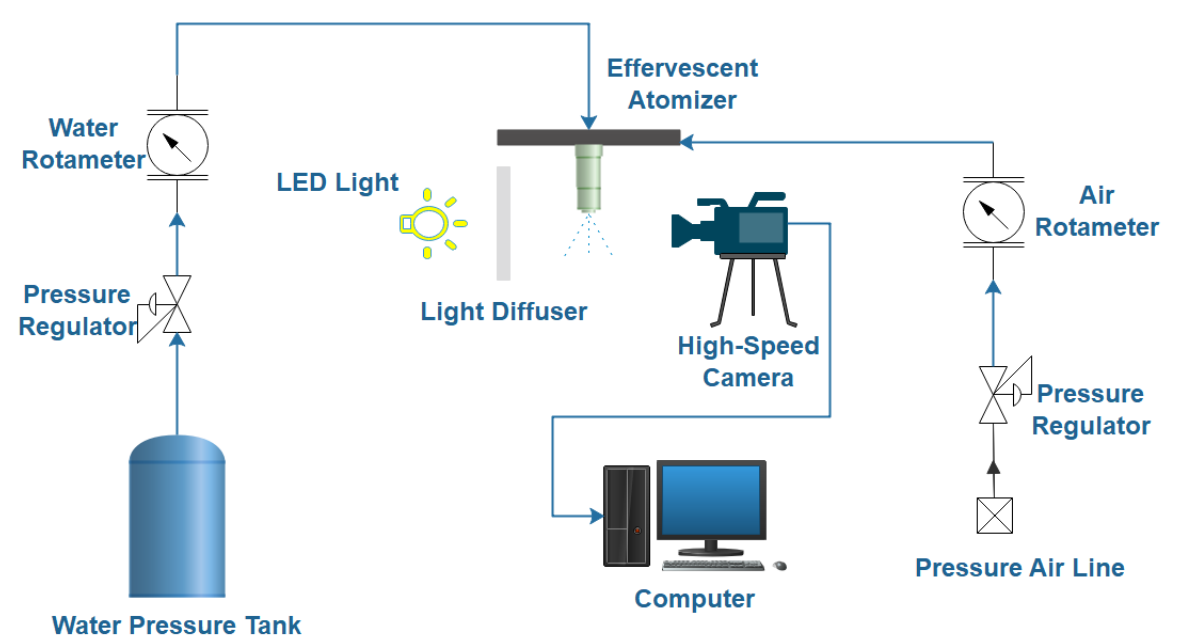

Fig. 2: Schematic of the experimental setup. 
Table 1: Experiment conditions.

\begin{tabular}{|c|c|c|c|c|c|}
\hline Test number & $\begin{array}{c}\text { Water flowrate } \\
(\mathrm{mL} / \mathrm{min})\end{array}$ & $\begin{array}{l}\text { Gas flowrate } \\
\text { (mL/min) }\end{array}$ & GLR \% & $\begin{array}{l}\text { Imaging view } \\
\text { (axis) }\end{array}$ & $\begin{array}{c}\text { Water and gas tank } \\
\text { pressure (MPa) }\end{array}$ \\
\hline 1 & 397 & 1780 & 0.54 & Minor & 0.35 \\
\hline 2 & 397 & 4125 & 1.25 & Minor & 0.35 \\
\hline 3 & 397 & 6275 & 1.9 & Minor & 0.35 \\
\hline 4 & 397 & 8423 & 2.55 & Minor & 0.35 \\
\hline 5 & 397 & 1780 & 0.54 & Major & 0.35 \\
\hline 6 & 397 & 4125 & 1.25 & Major & 0.35 \\
\hline 7 & 397 & 6275 & 1.9 & Major & 0.35 \\
\hline 8 & 397 & 8423 & 2.55 & Major & 0.35 \\
\hline
\end{tabular}

\section{3. spray angle measurement}

For each test, 5000 frames were recorded to calculate the spray angle at $10 \mathrm{~mm}$ from the nozzle exit. Moreover, 1000 frames were captured without the spray as the background images. The spray angle was measured on the average image, wherein each pixel contains the average intensity of all frames. To reduce the effect of spray fluctuation and have an unchangeable spray domain, a minimum of 800 images are required for getting an average image of spray independent from the number of frames. By using the Image J software, the average background image was subtracted from the average spray image. Then a threshold of $90 \%$ was applied to determine the spray edge on the resultant image. This threshold value has been used in other studies [12], [13]. A tangent line drawn to the spray periphery determines the spray radius, R2 (in mm), at the stand-off distance of $10 \mathrm{~mm}$. At each imaging view, R1 (in $\mathrm{mm}$ ) is the orifice radius (major or minor axis). The angle between the tangent line and the vertical line, which connects the orifice exit to R2, shows the spray half-angle (= $\left.\tan ^{-1}((R 2-R 1) / 10)\right)$. Fig. 3 demonstrates the average image and the thresholded image for test number 5 .

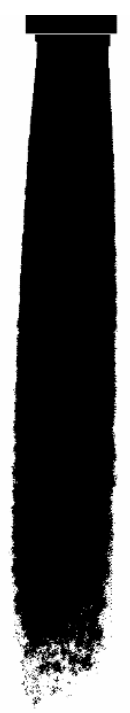

a)

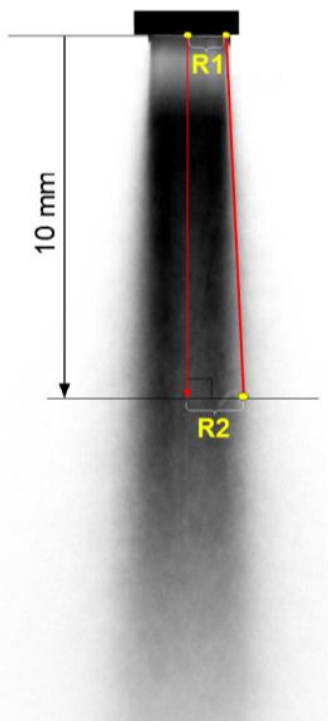

b)

Fig. 3: Spray angle measurement using the ImageJ software. a) thresholded image, b) average image after background subtraction. 


\section{Results and discussion}

Fig. 4 shows the spray angle variations of the minor and major views at different GLRs. It can be seen that an increase in the gas flowrate (i.e., increase in GLR) causes a rise in the spray angle for both major and minor views. It is evident that as the amount of gas flow rate increases, the energy of atomizing gas gets larger to burst bubbles when they go through the nozzle exit. As a result, the aerating gas atomizes water in the broader area with a larger spray angle. The other parameter which affects the spray angle is the orifice shape and its diameter. At a particular GLR, the spray angle is broader from the minor axis view compared with the major axis view. This phenomenon is apparent in Fig. 5. Another intriguing conclusion that can be made from this figure is that as the amount of GLR increases, the difference between the spray angle of major and minor views increases. The smaller diameter of the exit orifice in the minor axis causes a wider spray due to the stronger air bubble bursting.

a)

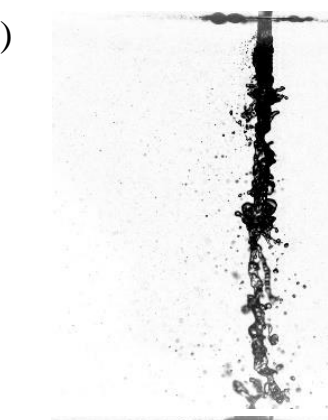

b)

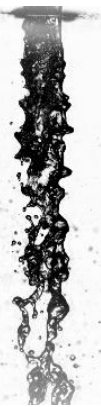

GLR $0.54 \%$

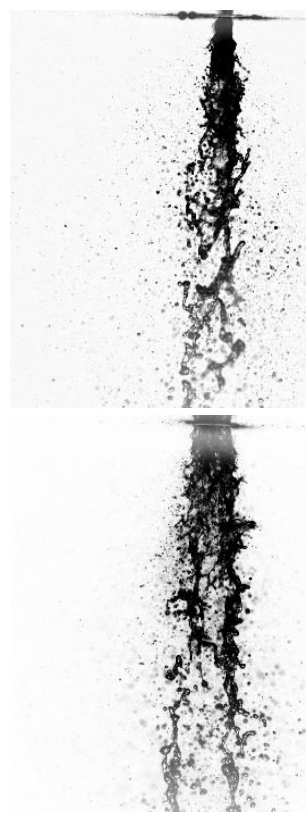

GLR $1.25 \%$

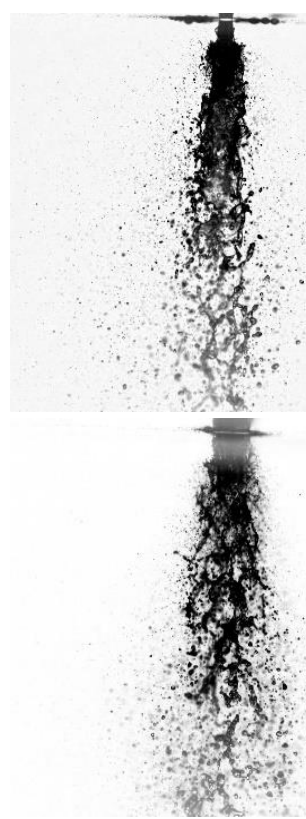

GLR $1.9 \%$

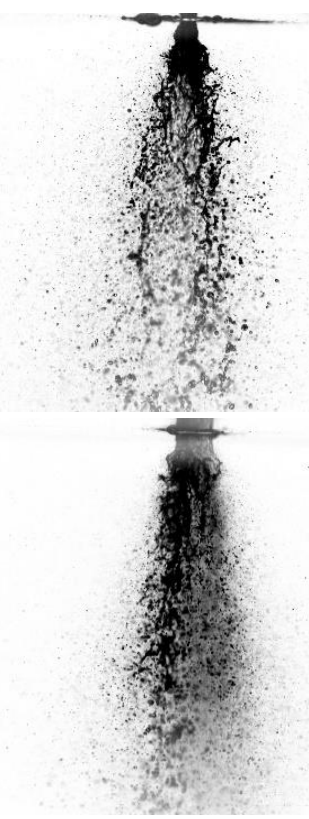

GLR $2.55 \%$

Fig. 4: spray at different GLRs. a) minor axis view, b) major axis view.

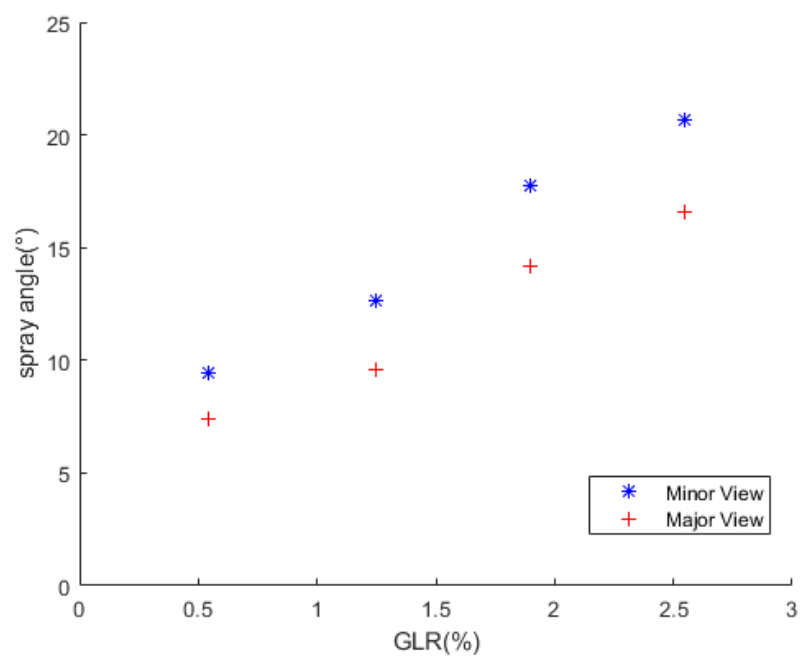

Fig. 5: Effect of GLR on the spray angle from two imaging views. 


\section{Conclusion}

Spray angle is experimentally investigated by using the high-speed shadowgraph images for an elliptical effervescent atomizer. For each test case, the average image, which is the superimposition of 800 frames, is used to measure the average spray angle. The effect of GLR on the spray angle from the two minor and major axis views is studied. It is found that the spray has a wider angle from the minor view in comparison with the major view. The reason is that the smaller diameter of the orifice from the minor view increases the power of bubble bursting, which splashes water in a broader domain. Furthermore, the energy of aerating gas depends on the amount of air that exists for the atomization of water. As the GLR increases with a rise in the gas flowrate, the spray angle will increase; for example, the spray angle at the GLR of $0.5 \%$ is approximately 8 degrees, which goes up to 20 degrees at the higher GLR of $2.55 \%$.

\section{Acknowledgments}

The authors would like to thank the financial support of Natural Sciences and Engineering Canada (NSERC).

\section{References}

[1] S. D. Sovani, P. E. Sojka, and A. H. Lefebvre, "Effervescent atomization," Prog. Energy Combust. Sci., vol. 27, no. 4, pp. 483-521, Jan. 2001.

[2] M. Mousavi and A. Dolatabadi, "Numerical study of the effect of gas-to-liquid ratio on the internal and external flows of effervescent atomizers," Trans. Can. Soc. Mech. Eng., vol. 42, no. 4, pp. 444-456, Jun. 2018.

[3] S. K. Chen and A. H. Lefebvre, "Spray cone angles of effervescent atomizers," At. Sprays, vol. 4, no. 3 , 1994.

[4] R. A. Wade, J. M. Weerts, J. P. Gore, and W. A. Eckerle, "Effervescent atomization at injection pressures in the MPa range," At. Sprays, vol. 9, no. 6, 1999.

[5] S. D. Sovani, E. Chou, P. E. Sojka, J. P. Gore, W. A. Eckerle, and J. D. Crofts, "High pressure effervescent atomization: effect of ambient pressure on spray cone angle," Fuel, vol. 80, no. 3, pp. 427-435, Feb. 2001.

[6] T. V. Kasyap, D. Sivakumar, and B. N. Raghunandan, "Flow and breakup characteristics of elliptical liquid jets," Int. J. Multiph. Flow, vol. 35, no. 1, pp. 8-19, Jan. 2009.

[7] J. G. Hong, K. W. Ku, S. R. Kim, and C.-W. Lee, "Effect of cavitation in circular nozzles and elliptical nozzles on the spray characteristic," At. Sprays, vol. 20, no. 10, 2010.

[8] J. Jedelsky, J. Otáhal, and M. Jicha, "Effervescent atomizer: influence of the internal geometry on atomization performance," 2007.

[9] D. W. Loebker and H. L. Empie Jr, "Effervescent spraying: a new approach to spraying high solids black liquor," 1998.

[10] J. Karnawat and A. Kushari, "Controlled atomization using a twin-fluid swirl atomizer," Exp. Fluids, vol. 41, no. 4, p. 649, Aug. 2006.

[11] X. Huang, X. S. Wang, and G. X. Liao, "Characterization of an effervescent atomization water mist nozzle and its fire suppression tests," Proc. Combust. Inst., vol. 33, no. 2, pp. 2573-2579, Jan. 2011.

[12] A. Saleh, G. Amini, and A. Dolatabadi, "Penetration of aerated suspension spray in a gaseous crossflow," At. Sprays, vol. 28, no. 2, 2018.

[13] K.-C. Lin, P. Kennedy, and T. Jackson, "Penetration heights of liquid jets in high-speed crossflows," in 40th AIAA Aerospace Sciences Meeting \& Exhibit, American Institute of Aeronautics and Astronautics. 